\title{
The Role Of Person Job Fit And Person Organization Fit On The Development Of Innovation Capabilities At Indonesia Creative Industry
}

\author{
Nikolas F. Wuryaningrat, Paulus Kindangen, GreisSendouw, Bode Lumanouw
}

\begin{abstract}
Through the study, it was assuming that in order to develop the innovation capabilities of SMEs in the creative industry, knowledge sharing is needed, where trust is a crucial factor in knowledge sharin. However, building trust is not a simple matter, it assumed that person job fit (PJ-Fit) and person organization fit (PO-Fit) could be useful to build trust in the organization. Two hundred and one data were collectedfrom Province of Bali, Province of Special RegionYogyakarta and North Sulawesi Province. Data were analyzed with PLSSEM.The study proposed four hypothesis and the results indicated there is no significant direct effect relationship between person job fit (PJ-Fit) and person organization fit (PO-Fit) on innovation capabilities. Result also indicated there is significant effect PJ-Fit and PO-Fit on trust, hence trust make positive effect on knowledge sharing, in turn knowledge sharing had positive significant effect on creative industry innovation capabilities at Indonesia.
\end{abstract}

Keywords: knowledge sharing, innovation capabilities, person job fit, person organization fit, trust.

\section{INTRODUCTION}

The capability of a large scale or small firm to produce competitiveness depends on its ability to manage its knowledge resources (Nonaka and Takeuchi, 1995; Grant, 1996; DuPlesis, 2007). Innovation is the only way to make sure organization have their sustainable competitiveness (Johannessen et al., 2001).

This research focuses on small and medium enterprises (SMEs) creative industry in Indonesia due of their several issues. Indonesia Ministry Cooperation and SMEs released the report that creative industry had $6.46 \%$ contribution on Gross Domestic Product (GDP) in 2017. Even tough, SMES creative industry has positive contribution on Gross Domestic GDP but the value is still under other ASEAN countries such as Malaysia, Thailand, and Singapore.Global Competitiveness Index (GCI) released annual report that in 2017 Indonesia had positive development on competitiveness which succeeds to reach number three in Asian Countries. Even tough, if compared with Singapore and Malaysia, Indonesia is still far left behind.It can conclude, Indonesia creative industry has to extend their

Revised Manuscript Received on April 19, 2019.

Nikolas F. Wuryaningrat, Management, UniversitasNegeri Manado, Manado, Indonesia. (Ph.D Student from Universitas Sam Ratulangi, Indonesia)

Paulus Kindangen, Management, Universitas Sam Ratulangi, Manado Indonesia

GreisSendouw, Management, Universitas Sam Ratulangi, Manado Indonesia

Bode Lumanouw, Management, Universitas Sam Ratulangi, Manado Indonesia

innovativeness through their knowledge.Darroch (2005) opinion, organization that is capable of managing knowledge will become a more innovative company. According to Argote et al. (1999), knowledge sharing is fundamental part of knowledge management due of their relation to optimizing knowledge stock.Knowledge sharing will create a new knowledge that could be used to evolve innovation capabilities (Lin, 2007).

Although knowledge sharing is very important to a organization, one of significant problem is that knowledge sharing does not emerge automatically (Szulanski, 1996). Knowledge sharing is a complicated process because of the different perceptions of knowledge givers and knowledge receivers (Shannon and Weaver, 1949).Meanwhile, other opinion stated that knowledge sharing is "one shot" and instant process due of technology diffusion will be happen anyway in organization (Nelson, 1981).

Communication can be done if the two sides could understand each other andhave mutual agreement, same mind, knowledge, same vision etc. If this condition not occurs, then knowledge sharing will be 'sticky' does make sense (Szulanski, 1996). On the other hand, if the between individual could have mutual trust then it is possible individual will lead to their knowledge openness. The organizational trust is critical to knowledge sharing process. Davenport and Prusak (1998) state that knowledge sharing is need 'common language'.If trust can build then knowledge sharing is "one shot" process does make sense (Nelson, 1981).

To discuss differences, it is predicted trust is essential factor. When there is a form of trustworthiness between all the elements in an organization, it is possible knowledge sharing will be more easily occur in the organization (Bartol and Srivastava, 2002; Tsai,2002,Minbaeva, 2014).

However, it is not so easy to position trust and knowledge sharing within an organization even when there is many number of fact describe about important benefits for organizations and their members (Kramer, 1999). For instance, a little difference between individuals' competencies possible to trigger conflict (see McAllister, 1995). It is suggest trust could easily to build if the empoyeesfit with their jobs. Person-job-fittheory (PJ-fit) andperson-organization-fit theory (PO-Fit).Kristof and 
Brown, (1996) argue employee need to adjust their knowledge, skill ,ability andtheir individual value with the organization need. If the person cannot fulfill their fit it is believed will make the difficulty in trust building process. In this context of research, trust could built as the effect of the knowledge, skill, ability, and values fit in an organization.

This research will simultaneously see causal relations betweenPJ-Fit and PO-Fit on deploy innovation capabilities, through trust and knowledge sharing. It is predicted PJ-Fit and PO-Fit could create the employee fit with their specific job and values on organization needed. Strong suggest with employee fit then organization will be easier to expand organizational trust, in knowledge sharing process on organization could be expected to create the necessary innovation capability.

\section{LITERATURE REVIEW AND HYPOTHESIS}

Knowledge based view theory explain that knowledge have been considered as fundamental resource for the organization (Grant, 1996). Knowledgeis the center of successful business (Prahalad and Hamel, 1990;Nonaka and Takeuchi, 1995).

Kristoff and Brown (1996) defined PJ-Fit as the fit between knowledge, skill, and ability with the job description. Kristoff and Brown (1996) PJ-Fitcan be evaluated from the subjective and objective sides. Evaluation from the subjective side is a individual perception about employee adjustmentwith their ability and the job. Meanwhile, from the objective side is to comparedthe work result with other individual with similar job description.

$\mathrm{P}-\mathrm{O}$ Fit is a fit between the individual value and the organization's value (Kristoff, 1996). PO-Fit see the relation between individual value with the job description information and organization interest, therefore individual could be join the organization based on their interest and organization can hire employee also based on organization value (Lee and $\mathrm{Wu}, 2011$ ). The firm,can be a place where individuals meet with their interest, vision, goals (Caplan, 1987).

Trust define "The extent to which a person is confident in, and willing to act on the basis of, the words, actions and decisions of another" (McAllister, 1995). Trust will make individual take risk, and trust will provide feeling where someone else will not take advantage only for personal interest (McAllister, 1995). Trust also a form as what people have expected in getting something and not worrying about it. Trust consist of two dimensions, which is cognitive trust and affection trust (McAllister, 1995). Cognitive trust is based on honor, knowledge or any other emotional reasons. Affective trust is a form of caring attitude to the colleagues as an investment, they belief theirpartner will do the same in return. Trust is influential for themanagement;it is believed trust will boost business performance and innovation (Hisrichet al. 2017).

Tom, (1971) argue most people will choose their environment with the same 'personality'. Job embeddedness theory explains employee hearts and minds are closely related to the suitability of individual values with organizational values (Zhang et al. 2013). Employee could feelfit with his work and work environment will be more easier to build trust between individuals. PJ-Fit and PO-Fit positively influence the climate of innovation when innovation trust were build (Afsaret al.,2015). Covella (2017)stated thatPJ-Fit and PO-Fit could create employee engagement and reduce the risk of employees leaving their jobs driven by organizational trust.

From the explanation above, hypotheses one can be drawn out.

\section{Hypothesis 1a: PJ-Fit has a positively affect on trust.}

\section{Hypothesis 1b: PO-Fit has a positively affect on trust.}

Knowledge sharing is a form of continuous learning that closely related to the creation of new contexts, new views and new knowledge (Kamasak and Bulutlar, 2009; Nonaka et al. 2006). Knowledge sharing define as the process of exchanging tacit knowledge and explicit knowledge to produce new knowledge (Hoof and Ridder, 2004). Knowledge sharing is an individual activities of giving ideas, suggestions, information, experience and expertise to the other (Hoof and Rider, 2004; Bartol and Srivastava, 2002).

According to Davenport andPrusak (1998) the existence of trust in organizations could help the knowledge sharing process.Further explained by Levin et al. (2002), knowledge sharing needs trust. It is strong suggest, knowledge sharing will be underutilized if there is no trust. Organizational trust will create a feeling which believed other employee will not take personal advantage (McAllister, 1995).Therefore, through the organizational trust, the individuals in the organization will open their willingness to share what he/she has, including their knowledge. As mention earlier, trust can consider as a investment due trust could provide feeling individuals will not feel loss to gave what he/she know. They actually feel they will get things that are considered profitable.

Chang and Chuang (2011) in the research revealed that the trust that exists in the company will affect the quantity and quality of knowledge sharing. Park and Lee (2013) indicated that team members would share their knowledge when they trusted their colleagues and felt dependent on the existence of their colleagues.

Accordingly, the second hypothesis can be stated as follows:

\section{H2 : trust has positively impact on knowledge sharing}

Wernerfelt (1984) and Grant (1996) argue innovationrequires knowledge resource. Davenport Prusak (1998) stated about knowledge stock which can be increased from new knowledge and existing knowledge. Knowledge stockcan provide opportunities for organization achieved their innovation performance and capability (Tsai, 2001; DuPlesis, 2007).The definition of innovation is very diverse but refers to one conclusion that is innovation as a form of novelty. Johannessen et al. (2001) define innovation as a form of novelty that aims to create and maintain sustainable competitiveness.
Blue Eyes Intelligence Engineering \& Sciences Publication 
Knowledge could provide a reactive ability to respond to business change, which in turn organization higherinnovation capabilities (Lin, 2007). Wang and Wang (2012) give empirical evidence that knowledge tacit and explicit sharing can facilitate innovation in information technology firm at China. Knowledge sharing between organizational members tends to generate new ideas for developing process and product innovations. Furthermore knowledge sharing will develop innovation and competitive advantage and organizational performance in small and medium enterprises (Ngah and Jussof, 2009).

In emerging country like Indonesia, a similar study also concludes that knowledge sharing will provide positive benefits for improving the innovation capabilities of SME production sectors in North Sulawesi, Indonesia (Wuryaningrat, 2013).Mulyana and Wasiowati (2015) gave empirical evidence in small and medium-sized Batik companies were showed that both knowledge donating and knowledgecollecting significantly affected on innovation capabilities.

As previously explained, knowledge sharing aims to gain knowledge from internal sources or external sources. Thus, small or largerfirm should open their interaction to knowledge sources such as consumers and suppliers or other sources.For instance, innovation at SMEsproduct furniture in the city of Yogyakarta was derived from its interaction with consumers, consumers will produce the latest models that consumers need (Indarti, 2010). The key success Toyota becoming the biggest automotive company is knowledge sharing activitybetween producers and suppliers (Dyer and Nobeoko, 2000).

From the explanation above, hypotheses three can be drawn out.

$H 3$ : knowledge sharing has a significant effect on Innovation capabilities.

From the all explanation above, it can also conclude PJFit and PO-Fit seem could not make any direct influence to innovation capabilities. The logical framework explain that PJ-Fit and PO-Fit will make affect first on trust and knowledge sharing before innovation capabilities can increase. Hence, hypotheses four can be drawn out.

$\mathrm{H} 4 \mathrm{a}$ : trust and knowledge sharing mediated the influence of PJ-Fit on innovation capabilities.

$\mathrm{H} 4 \mathrm{~b}$ : trust and knowledge sharing mediated the influence of PO-Fit on innovation capabilities.

The explanation of these logical theories with the development of the hypothesis can be summarized in Figure 1 .

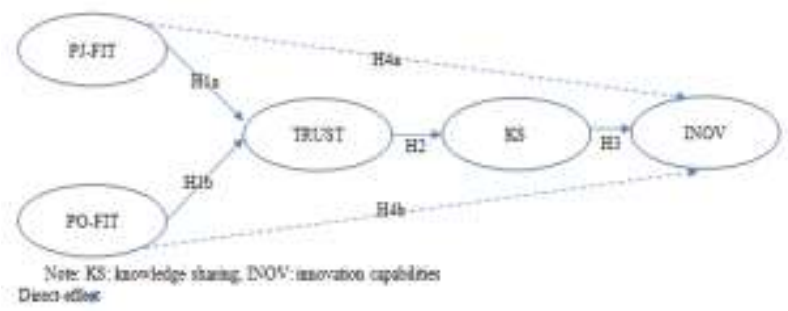

Figure 1. Conceptualized Model

\section{RESEARCH METHOD AND MEASUREMENT}

This research was designed with survey approach. Respondents in the study are the owners or managers of creative industry SMEs. Non-random purposive samplings were used. The criteria for selecting respondents in this study are as follows: SME creative industries that have existed for more than 3 (three) years, SMES creative industries that have a permanent staff of 5-99 people, the creative industries used in this research are those engaged in the sub-sector the knowledge sharing activity craft products are relatively high (Indarti, 2010).

Special Region of Yogyakarta (DIY), Province Bali and North Sulawesi (Sulut) were chosen to represent Indonesia.The questionnaires were distributed directly to two hundred and onerespondents.

This research consists of mediation variables of trust and knowledge sharing.The test of mediating effect has to measure the direct relationship between PJ-Fit and PO-Fit as independent variables and innovation capabilities as dependent variables and also measures the effect of indirect relationship between them by using a trust and knowledge sharing as mediating variable (Baron and Kenny 1986).

Constructs of Person job fit and person organization fit measurements used a questionnaire developed by Afsar et al. (2015). PJ-Fit consists of four item statement and three item statement for PO-Fit.The construct of trust weremeasured by a questionnaire developed by McAllister (1995), therewereelevenitems made.The knowledge sharing construct is measured by ten statement items developed by Hoof and Ridder (2004). Finally, innovation capabilities were measured by six questionnaire (Johannessen et al. 2001). The statements in the closed questionnaire use the Likert scale 1 to 5 ( $1=$ very rarely to $5=$ very often/almost always) to indicate the respondents' intensity level for answer choices.

Data analysis in this research consists of two ways, which are, data reduction (validity and reliability) and hypotheses testing. Data were analyzed with a structural equation model based on variant or PLS-SEM using SmartPLS 2.0 M3 software. The first way, will be explain on next session.

\section{VALIDITY AND RELIABILITY}

The convergent validity conducted to whether the research instrument correlates highly with the research construct. Loading factor higher than 0.5 and AVE value that is higher than 0.5 were the rule of thumb to consider as acceptable validity (Hair et al., 2010:695). Another convergent validity which is reliability test (Hair et al., 2010) were conducted, its assessment is based on composite reliability valuehigher than 0.7 . The results of validity and reliability can be seen in Table 1 . 
Table 1. Convergent Validity

\begin{tabular}{|l|c|c|c|c|}
\hline \multicolumn{1}{|c|}{ Construct } & $\begin{array}{c}\text { Remainin } \\
\text { g item }\end{array}$ & Factor Loading & AVE & $\begin{array}{c}\text { Composite } \\
\text { Reliability }\end{array}$ \\
\hline PJ-Fit & 4 & $0.684-0.833$ & 0.584 & 0,849 \\
\hline PO-Fit & 3 & $0.701-0.834$ & 0.626 & 0,833 \\
\hline Trust & 6 & $0.504-0.828$ & 0.510 & 0,858 \\
\hline $\begin{array}{l}\text { Knowledge } \\
\text { Sharing }\end{array}$ & 10 & $0.598-0.883$ & 0.532 & 0,839 \\
\hline $\begin{array}{l}\text { Innovation } \\
\text { capabilities }\end{array}$ & 5 & $0.646-0.870$ & 0.508 & 0,835 \\
\hline
\end{tabular}

Tables 1 show the results of the validity test that only 28 questionnaire statements can be used for collecting data. The other 6statement cannot be used because their factor loading value is less than 0.5 ; or cross loading problems occur (Hair et al. 2010). The factor loading scores of 28 items results in AVE values higher than 0.5 , and it means that the value fulfills the required convergent validity (see Hair et al. 2010).

\section{THE RESULT}

As shown in Table 2, the respondents taking part in this research consist of one hundred and forty-seven $\operatorname{men}(73.13 \%)$ andfifty-four women $(26.86 \%)$. The result, shows that men are more predominant as the owners of creative industry SMEs than women. All the owner or manager of SMEs of creative industry have average age is 40 years old.

Also shown in Table 2, which is the educational level of the respondents considered as high level of education. Data gained show that most creative industry SMEs owners or managers graduated either high school degree or bachelor degree with a balanced proportion $(49.25 \%$ for high school and $43.78 \%$ for bachelor level). The higher the level of education the owners or manager have, the more the SMEs could be used and assimilated knowledge (Indarti 2010).

Table 2. Profile of Respondent

\begin{tabular}{|l|l|c|c|}
\hline & \multicolumn{1}{|c|}{ Category } & $\begin{array}{c}\text { Number of } \\
\text { Respondent }\end{array}$ & Percentage \\
\hline Sex & a. Men & 147 & 73.13 \\
& b. Women & 54 & 26.86 \\
\hline The Age Average & \multicolumn{1}{|c|}{$39,76=40$} & & \\
\hline \multirow{4}{*}{ Education level } & a. Elementary school & 2 & 0.99 \\
& b. Junior high school & 12 & 5.97 \\
& c. High school & 99 & 49.25 \\
& d. Bachelor or above & 88 & 43.78 \\
\hline
\end{tabular}

After the data reduction or validity test was conducted with a good result (see table 1). The hypotheses test were feasible, the result are shown in figure 2 .

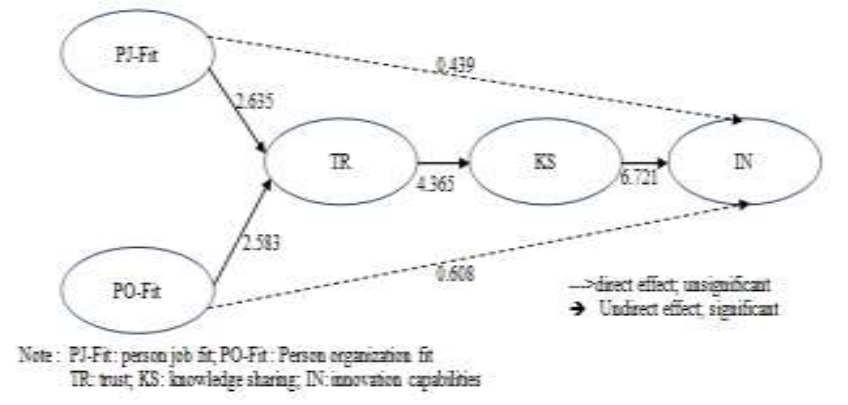

Figure 2. Path diagram of Conceptualized Model

As it can be seen in figure 2, PJ-Fit has significant impact on the trust. The result shows that the t-stat value is equal to 2.635 which is higher than t-stat minimum value 1.960 considered as acceptable value (Hair et al. 2010). In other words, H1a were supported. For $\mathrm{H} 1 \mathrm{~b}$, the finding also supported the hypothesis because of t-stat value is 2.583 higher than 1.960. Thus, it can be concluded that the PO-Fit has significant impact on trust.

Later on, H2 were supported due trust has significant impact on knowledge sharing. T-stat value is 4.365 which higher than 1.960 value. Afterward, H3 is also has significant impact due of t-stat value is wqual to 6.712 which is higher than 1.960. It can be concluded, knowledge sharing also make significant effect on innovation capabilities.

PJ-Fit has insignificant direct effect on the innovation capabilities. The result shows that the t-stat value is equal to 0.439 which is lower than t-stat 1.960 . In other words, H4a supported. For $\mathrm{H} 4 \mathrm{~b}$, the finding also supported the hypothesis because of t-stat value is 0.608 which is lower than 1.960. Thus, it can be concluded that the PO-Fit has an insignificant direct impact on innovation capabilities. From the result of the fourth hypothesis, it can be concluded that PJ-Fit and PO-Fit could not act as a direct effect on innovation capabilities. Meanwhile, from the result it can also concluded that trust and knowledge sharing succeed play the role as mediating effect.

Baron and Kenny (1986) argue that the mediating effect has to reach the condition which is the direct effect have to insignificant. If the result is insignificant direct effect, this condition is regarded as fully mediated. The research result shown that the PJ-Fit and PO-Fit has insignificant direct effect on innovation capabilities, therefore trust and knowledge sharing construct will be fully mediated.

\section{CONCLUSION}

The above result gives a strong indication that PJ-Fit and PO-Fit cannot make direct impact on creative industry innovation capabilities. PJ-Fit and PO-Fit can develop innovation capabilities after trust in organization were build, and after trust success to build organization can create pleasant knowledge sharing environment. Knowledge sharing is still the key to create innovation (Wuryaningrat 2013; Hoof and Ridder, 2004).

Knowledge, skill and abilities in accordance with the needs of the company will give organization reliable and trustworthy employees. Hence, that condition will open the possibility of creating organizational trust. Beside that, according to research result identified that individual values that are in accordance with the organization values could play a significant role in buildingtrust. In other word, PJ-Fit and PO-Fit can create compatibility with the mindset and similarity of feelings in creative industry. Davenport and Prusak (1998) mention a form of 'common language' which has the same meaning ascompatibility with the mindset and similarity of feelings. In other word, to build organizational trust, organization requires employees who are able to fitwith the competencies and organization values.For instance, Google change as one of the biggest information and technology corporation due of their human resource strategy recruits and retain 'top people' (Filipovic et al, 2011). Google 'top people' strategy lies on their way to find employees which not only 'genius' but also can fit with the

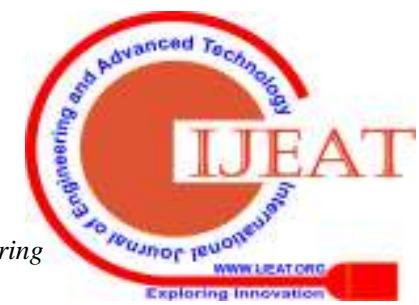


innovative environment their build.

Previous research mentioned trust is critical combination of knowledge sharing (Levin et al., 2002; McNeish and Mann, 2010; Davenport and Prusak, 1998). The result of study gave empirical evidence that knowledge sharing in creative industry will be useless without trust. Knowledge can either be treated as a raw material, which is a part of the process and is separate from the person, or integral to the person (Polanyi, 1966). Knowledge sharing is about the exchange of the knowledge between two or more individuals (McNeish and Mann, 2010). Hence, individuals will need a very strong trust to provide someone else their knowledge.People mayneed a long time and closeness to finally be willing to transfer his knowledge to his trusted person.

Knowledge sharing is a learning process drawing from many sources. Knowledge sharing is a learning process conducted in internal and external environments to gain new knowledge. Hoof and Ridder (2004) define knowledge sharing as the process of individual exchange their knowledge (tacit or explicit) and jointly to create new knowledge.Srivastava et al. (2006) argue knowledge will generate ideas, suggestion and information that useful to create innovation. Nonakaand Takeuchi (1995) ; Grant (1996) mentioned about knowledge as main resource to create sustainable competitiveness which shown with their innovation. In other word, knowledge sharing will be generate new knowledge to provide innovation. The study also reveal same result, it can be conclude in the creative industry will need knowledge sharing activity.

\section{ACKNOWLEDGMENT}

Authors thanks to Bank Indonesia Institute and DirektoratJenderalRiset and PengabdianMasyarakat, Ministry of Research Technology and Higher Education for financial support.

\section{REFERENCES}

1. I. Nonaka, and H. Takeuchi, The Knowledge-Creating Company: HowJapanese Companies Create the Dynamics of Innovation. New York: OxfordUniversity Press.1995.

2. R.M. Grant, R.M. Toward a knowledge-based theory of the firm. StrategicManagement Journal, vol. 17, 1996 , pp. 109-122.

3. M. Du Plessis, M., The role of knowledge management in innovation. Journal of Knowledge Management, Vol. 11, 2007, pp. 20-29.

4. J.A. Johannessen, B. Olsen, and G.T.Innovation as newness: what is new, how new, and new to whom?.European Journal of Innovation Management, vol. 4, 2001, pp. 20-21

5. C.K. Prahalad, G. Hamel.The core competence of the corporation.Harvard Business Review, Vol. 68(3), 1990, pp. 79-92.

6. Lee, Feng-Hui and Wann-Yih, Wu. The relationships adjustment, personality traits, andinnovative climate: Evidence from Taiwanese high-tech expatriate managersin Asian countries. African Journal of Business Management, Vol. 5(15), 2011, pp. 6415-6428.

7. R.D. Caplan, Person-Environment Fit Theory and Organizations:Commensurate Dimensions, Time between personorganizationfit, psychological climate

Perspectives, and Mechanisms. Journal ofVocational Behavior, Vol. 31, 1987, pp. 248-267

8. D.J. McAllister,Affect- and Cognition-Based Trust Formations for Interpersonal Cooperation in Organizations. Academy of Management Journal, vol. $36: 1,1995$, pp. 24-59

9. V.R., Tom, The role of personality and organizational images in the recruiting process. Organizational Behavior and Human Performance, Vol. 6:5, 1971, pp. 573-592

10. W. Tsai, Knowledge transfer in intraorganizational network: Effect of networkposition and absorptive capacity on business unit innovation andperformance. Academy of Management Journal, vol.44, 2001, pp.: 996-1004.

11. Peng Lin, To Share or Not to Share: Modeling Tacit Knowledge Sharing,Its Mediators and Antecedents. Journal of Business Ethics, 70:4, 2007, pp. 411-428.

12. Z. Wang, and N. Wang, Knowledge sharing, innovation and firm performance.International Journal of Expert Systems with Applications, Vol. 39, 2012, pp.8899-8908.

13. R. Ngah, and K. Jusoff. Tacit Knowledge Sharing and SMEs' Organizational Performance. International Journal of Economics and Finance, Vol. 1(1),2009, pp. 216-220

14. N.F. Wuryaningrat, Knowledge Sharing, Absorptive Capacity and InnovationCapabilities: Empirical Study on Small Medium Entreprises at NorthSulawesi, Indonesia. GadjahMada International Journal of Business, 15:1, 2013, pp. 61-77.

15. B. Afsar, Y. Badir., and Khan, MM. Person-job fit, person-organization fit andinnovative work behavior: The mediating role of innovation trust. Journal ofHigh Technology Management Research, 26, 2015, pp. 105116.

16. Van den,Hooff, B. and J.A. de Ridder. Knowledge sharing in context: theinfluence of organizational commitment, communication climate and CMCuse on knowledge sharing. Journal of Knowledge Management,vol. 8, 2004, pp. 117-130.

17. M. Polanyi, The tacit dimension. 1966, London: Routledge\& Kegan Pa

18. G. Szulanski, Exploring internal stickness: Impediments to the transfer of bestpractice within the firm. Strategic Management Journal, vol.17, 1996, pp. 27-43.

19. C. Shannon, and W. Weaver. The Mathematical Theory of Communication. 1949, Urbana, IL: University of Illiniois Press.

20. T. Davenport, and L. Prusak, 1998.

21. K.M. Bartol, and A. Srivastava. Encouraging knowledge sharing: the role oforganizational reward system. Journal of Leadership and OrganizationsStudies, vol. 9, 2002, pp. 64-76.

22. A. Mulyana, andWasiowati. Pengaruh Knowledge Donating dan Knowledge Collecting terhadap Innovation Capability: KasusPengembangan UKM Batik di ProvinsiJawa Tengah-Indonesia JurnalManajemendanTeknologi, Vol. 14, No. 3,2015 pp. 246-264

23. D.B. Minbaeva, D.B., T. Pedersen, Bjorkman, and I., Park, H.J., MNC knowledge transfer, subsidiary absorptive capacity and HRM. International Journal of Business Study, Vol. 45, 2014, pp. 38-51.

24. G. Covella,Person-Job Fit And Person-Organization Fit Influence On Turnover Intention: A Mixed Model Approach.2017 Trident University International, dissertation (unpublished) 
25. R. Kamasak, and F. Bulutlar.. The influence of knowledge sharing on innovation. European Business Review, Vol. 22, 2010, pp. 306-317.

26. R.M. Baron and D.A. Kenny. The Moderator-Mediator Variable Distinction in Social Psychological Research: Conceptual, Strategic, and Statistical Considerations. Journal of Personality and Social Psychology, Vol. 51(6), 1986, pp.1173-1182.

27. Park, Jun-Gi and Lee, Jungwoo, knowledge sharingsharing in information systemsdevelopment projects: Explicating the role of dependence and trust.InternationalJournal of Project Management, Vol. 32, 2014, pp. 153-165

28. B. Wernerfelt, B. A Resource Based View of The Firm. Strategic Management Journal, Vol. 5 (2), 1984, pp. 171180

29. N. Indarti, The Effect of Knowledge Stickiness and Interaction on AbsorptiveCapacity: Evidence from furniture and software Small and MediumEnterprises in Indonesia. Dissertation,2010, Groningen University.

30. J.H. Dyer, and K. Nobeoka. Creating and managing a high-performanceknowledgesharingnetwork: The Toyotacase. Strategic Management Journal,Vol. 21, 2000, pp.345-368

31. J. McNeish, and I, Mann, Knowledge Sharing and Trust in Organizations. The IUP Journal of Knowledge Management. Vol. 8 2010,https://www.researchgate.net/publication/22827139 5_Knowledge_Sharing_and_Trust_in_Organizations/do wnload

\section{AUTHORS PROFILE}

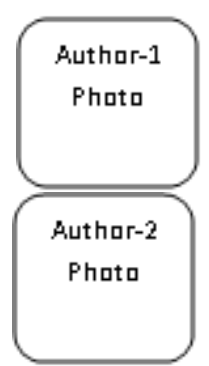

Authar-3

Phata
Nikolas F. Wuryaningrat, lecturer from Universitas Negeri Manado, Indonesia. He also a Ph.D student from Universitas Sam Ratulangi, Indonesia.

Paulus Kindangen, professor in Management at Universitas Sam Ratulangi.

GreisSendouw and Bode Lumanouw, senior lecturer from Universitas Sam Ratulangi 